\title{
UMA INVESTIGACCÃO SOBRE A AUTORIA DE DADOS CIENTÍFICOS: TEIAS DE UMA REDE EM CONSTRUÇÃO'
}

\begin{tabular}{c}
\hline AN INVESTIGATION INTO THE AUTHORSHIP OF SCIENTIFIC DATA \\
WEBS OF A NETWORK UNDER CONSTRUCTION \\
\hline UNA INVESTIGACIÓN SOBRE LA AUTORÍA DE LOS DATOS CIENTÍFICOS \\
WEBS DE UNA RED EN CONSTRUCCIÓN \\
Jackson da Silva Medeiros
\end{tabular}

Jackson da Silva Medeiros ${ }^{2}$

\section{RESUMO}

Este trabalho objetiva analisar a autoria científica a partir do compartilhamento de dados de pesquisa. Para esta finalidade, utiliza a Teoria Ator-Rede (ANT), a qual busca, a partir de uma ideia de simetria entre humanos e não humanos, não assumir uma divisão entre essas entidades, possibilitando visualizar o estabelecimento e a dissolução de uma rede a partir das relações que se criam em diversos níveis. Os dados que serviram de base para descrição e análise a partir da literatura foram recolhidos a partir de observação, de entrevistas e de materiais bibliográficos. A investigação ocorreu junto ao Repositório de Dados de Estudos Ecológicos do Programa de Pesquisa em Biodiversidade (PPBio). Conclui que os objetos conceituais e pragmáticos não podem ser vistos de maneira isolada, mas sim como atores-rede afetados diretamente pela tecnologia, devendo ser considerados atuantes importantes no processo de produção, compartilhamento e uso de dados digitais de pesquisa. A construção do fato científico e social autoria é coordenada por uma série de elementos, como a coleta de dados, a curadoria, os próprios dados científicos, seus metadados, as fontes de fomento, a política de dados, o repositório e seus softwares de gerenciamento e envio de dados e metadados, o licenciamento, a propriedade e a responsabilidade, agindo como um tipo de instrumentalização de um arranjo de fenômenos.

PALAVRAS-CHAVE: Autoria. Dados científicos. Repositório de dados. Teoria Ator-Rede.

\section{ABSTRACT}

This work aims to analyze the scientific authorship from the data sharing. For this purpose, it uses the Actor-Network Theory (ANT), which seeks, from an idea of symmetry between human and nonhuman, do not assume a division between those entities, allowing to view the establishment and dissolution of a network from the relationships that are created at different levels. The data collected, which were the basis for description and analysis from the literature that also emerged from what ware collected by observation, interviews and bibliographic materials. The study was carried out by the Repositório de Dados de Estudos Ecológicos do Programa de Pesquisa em Biodiversidade (PPBio). Concludes that conceptual and pragmatic objects can not be seen in isolate way, but like actors directly affected by the technology, should be considered important actants in the process of production, sharing and use of digital research data. The construction of scientific and social fact authorship is coordinated by a number of elements, such as data collection, curation, scientific data and its metadata, funding sources, data policy, repository and its management software for data and metadata, licensing, ownership and responsibility, acting like a kind of exploitation of a phenomena arrangement.

KEYWORDS: Authorship. Scientific data. Data repositor. Actor-Network Theory.

\footnotetext{
${ }^{1}$ Trabalho resultante de tese defendida pelo autor junto ao Programa de Pós-Graduação em Comunicação e Informação da Universidade Federal do Rio Grande do Sul em maio de 2015.

${ }^{2}$ Doutor em Comunicação e Informação pela Universidade Federal do Rio Grande do Sul. Professor do Departamento de Ciências da Informação na mesma Universidade. Porto Alegre, Rio Grande do Sul - Brasil. http://orcid.org/0000-00016725-4660. Email: jackson.medeiros@ufrgs.br.
}

Submetido em: 08-03-2016 - Aceito em: 12-05-2016. 


\section{RESUMÉN}

Este estudio tiene como objetivo analizar los autores científicos de intercambio de datos de la encuesta. Con este fin, utilizar la teoría del actor-red (ANT), que busca, a partir de una idea de simetría entre el ser humano y no humano, no asuma una división entre esas entidades, lo que permite ver la creación y disolución de una red a partir de las relaciones que se crean en los distintos niveles. Los datos que sirvieron de base para la descripción y el análisis de la literatura se obtuvieron de observación, entrevistas y material bibliográfico. La investigación se llevó a cabo en el Programa de Investigación Ecológica depósito de datos de investigación sobre la biodiversidad (PPBio). Se llega a la conclusión de que los objetos conceptuales y pragmáticos no pueden verse de manera aislada sino como afectados network-actores directamente por la tecnología, y debe considerarse importante en el proceso de producción activa, el intercambio y uso de los datos digitales de investigación. La construcción de los hechos científicos y la autoría social está coordinado por una serie de elementos, tales como la recopilación de datos, curación, propios datos científicos, sus metadatos, las fuentes de desarrollo, la política de datos, el repositorio y su software de gestión y el envío de datos y metadatos, la concesión de licencias, la propiedad y la responsabilidad al actuar como una especie de instrumentalización de una disposición de fenómenos.

PALABRAS CLAVE: Autoría. Datos científicos. Repositorio de datos. Actor-Red Teoría

\section{INTRODUÇÃ̃o}

Entendendo que os dados científicos são insumos para novas pesquisas e também o produto delas, consideramos que eles aumentam o poder comunicacional e informacional dos pesquisadores. Neste caso, são necessários estudos capazes de especificar como se (re)organiza a comunicação científica - e como parte disto a questão da autoria -, uma vez que, em virtude da novidade e consequente pouca existência de literatura referente ao tema, ainda existem preocupações incipientes sobre a utilização desse tipo de dados para o desenvolvimento científico, fazendo com que os esforços sejam alocados, em geral, em níveis computacionais, com vistas a melhorar o processamento e a transmissão de grandes quantidades dos mesmos.

Compreendemos que o compartilhamento de dados constitui-se a partir de uma infraestrutura informacional, isto é, artefatos de tecnologias da informação e da comunicação necessários para o processo dos resultados de pesquisa, bem como de sua face correspondente às relações implícitas e explícitas de regras, interesses, anseios, decisões etc. Assim sendo, essas relações estão em níveis micro e macro, podendo ser percebido que o compartilhamento está baseado em associações dos mais diversos tipos, circunscrevendo entidades de natureza variável.

Tomando a ideia de que a grande movimentação científica do mundo e a geração de dados em muitos campos acarreta o crescimento contínuo e em larga escala do modo como a comunicação científica vem se apresentando, a autoria é um processo complexo que está circunscrito desde a coleta dos dados, passando pela curadoria, compartilhamento, acesso e (re)uso desses dados. Este é nosso mote de estudo.

A autoria é uma questão de pesquisa que envolve problemas ainda não discutidos, principalmente quando falamos sobre autoria de dados científicos. Isso se dá porque, além da incipiência e complexidade do tema, os trabalhos que buscam tratar essa matéria o fazem tendo como ponto de partida os documentos bibliográficos, especialmente artigos científicos e livros, mas também teatro, cinema etc. Dados primários, além de considerados,

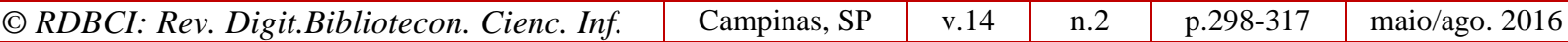


impropriamente, apenas como insumo de pesquisa, não despertaram, até o momento, interesse sobre o entendimento de sua autoria.

A pretensão do trabalho é analisar uma parte da infraestrutura de comunicação científica do compartilhamento de dados de pesquisa com vistas a compreender a autoria de dados científicos, uma vez que pode revelar estruturas explícitas e implícitas através de construtos sociais/coletivos, indo além do gerenciamento e tratamento de dados (curadoria). A importância desse tipo de abordagem é corroborada por Borgman (2010) ao anotar que a publicação de dados não possui os mesmos incentivos do que a publicação bibliográfica.

Sendo assim, o foco está direcionado a analisar a questão da autoria a partir do compartilhamento de dados de pesquisa, compreendendo que sua construção é socialmente dada. A partir disso, podemos notar que objetos e/ou conceitos, quaisquer que sejam, mantêm relações entre si através de um conjunto de atividades, sendo suas existências objeto de análises que envolvem suas interdependências a partir de variáveis que se formam como uma rede, envolvendo questões que estão conectadas e que só podem persistir a partir da existência de outros atores, humanos ou não, que sustentam a rede.

\section{METODOLOGIA: TEORIA ATOR-REDE PARA A COMPREENSÃO DE REDES SOCIOTÉCNICAS}

Para esta empreitada de caráter qualitativo, buscamos pensar este estudo sobre a autoria de dados científicos com base na movimentação dos actantes envolvidos no processo de (re)organização da comunicação científica a partir do viés do compartilhamento de dados de pesquisa, percebendo o que está intimamente relacionado com as manifestações associativas dos atores-rede. Utilizamos para isso a Teoria Ator-Rede (ANT), a qual, a partir da existência de uma simetria entre humanos e não humanos, isto é, não assumir uma divisão entre humanos e não humanos, visa possibilitar que uma rede se estabeleça, se modifique e se dissolva a partir das relações que se estabelecem em diversos níveis. Esses atores-rede, actantes, estão mobilizados para a estruturação de redes temporárias a partir de um programa de ações, através da transformação e da modificação do significado ou dos elementos que veiculam.

A Teoria Ator-Rede se opõe aos estudos ditos sociais, os quais buscam a existência de um contexto social que influencia, que atua e que estabelece características explicativas por sua categorização. Isso significa dizer que as explicações aceitas pela ANT não dizem respeito a existência de "mãos invisíveis" (contextuais) que seriam capazes de controlar (categorizar) e/ou explicar determinada situação. Se a causa de determinada ação for uma relação política, por exemplo, então a política das ações executadas e que formam a rede deve ser descrita para que então sejam explicadas.

À luz de Latour, a ideia de rede proposta pela ANT é uma nova forma de encarar a problemática da "produção social do conhecimento científico", porque ela "se conecta ao mesmo tempo à natureza das coisas e ao contexto social, sem contudo reduzir-se nem a uma coisa nem a outra" (LATOUR, 2009, p. 11). Como aponta Moraes (2004), uma rede é uma

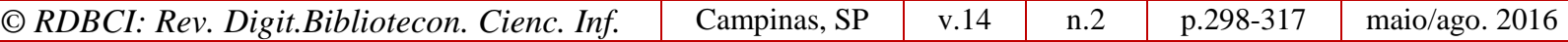


lógica de conexões e não de superfícies, definidas por seus agenciamentos internos e não por seus limitadores externos, não existindo pontos que mereçam ser privilegiados, caracterizando uma totalidade aberta e capaz de se relacionar e crescer em todas as direções.

A ANT, abrindo mão de uma suposta linha divisória entre humanos e não humanos, percebe as entidades como uma grande rede conectada e que se modifica constantemente a partir das relações que se estabelecem em diversos níveis. Como ressaltam Moraes (2004) e Freire (2006), não há previamente uma separação entre o mundo das pessoas e o mundo das coisas. Estes elementos se reúnem e se engendram de forma a não levar em conta princípios essencialistas. Assim sendo, compreender essa configuração permite ir adiante, apoiados em uma perspectiva que não aceita categorizações prévias.

O que se deve apreender é a complexidade que envolve o processo. Neste passo não é mais importante privilegiar um humano a um não-humano ou vice-versa. A investigação deve levar em conta a proliferação de actantes que sejam relevantes ao caso. Assim, assumimos que "[...] atores humanos e não humanos agem em rede e constituem-se eles mesmos como rede. Não há claramente sujeito e objeto, nem causa ou efeito predeterminados. Cada nó de uma rede de ação [...] convoca uma série de atores humanos e não humanos" (LEMOS, 2010, p. 16).

De forma mais clara, podemos definir actante de acordo com Latour (2001, p. 346):

O segredo é definir o ator com base naquilo que ele faz - seus desempenhos - no quadro dos testes de laboratório. Mais tarde, sua competência é deduzida e integrada a uma instituição. Uma vez que, em inglês, a palavra actor (ator) se limita a humanos, utilizamos muitas vezes 'actant' (atuante), termo tomado a semiótica, para incluir não-humanos na definição. (LATOUR, 2001, p. 346).

Reivindicando o chamamento de uma rede sociotécnica, na realidade o que invocamos é uma dinâmica associativa entre actantes, sejam eles humanos ou não, sendo importante notar agora que não há forma na rede, apenas movimentos. Movimentos que designam formas novas e diferenciadas.

Esse processo é conduzido pelo que Latour (2012, p. 158) chama de tradução ou de translação. O conceito de tradução é de suma importância para a ANT, tal que a Teoria pode ser chamada de Teoria da Tradução. Seu mérito está na "interpretação dada pelos construtores de fatos aos seus interesses e aos das pessoas que eles alistam" (LATOUR, 2000, p. 178). Isto é, refere-se a "hibridação, mestiçagem, multiplicidade de conexões mais do que à repetição de elementos-chave. A tradução é sustentada por uma ontologia definida por sua hibridação" (MORAES, 2004, p. 326). Essa mistura subjetiva aportada pela tradução é que alimenta a origem do conhecimento, indo além da simples interação linear entre humanos.

A tradução diz respeito as modificações a que os actantes estão propensos durante a vigência do programa, sendo alvos de deslocamentos e negociações, responsáveis pela moldagem entre as associações que formam o social, colocando-os como elementos representativos em uma rede. Isto permite que um discurso cresça e permita clarificar os complexos processos que em que o social está envolto (PEREIRA, 2013).

Agora é possível introduzir dois conceitos essenciais à ANT: intermediários e mediadores (LATOUR, 2012, p. 65). O primeiro diz respeito a "aquilo que transporta

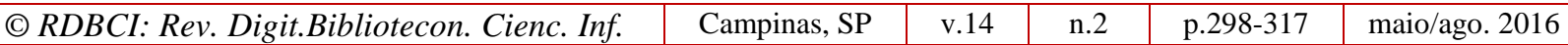


significado ou força sem transformá-los; definir o que entra já define o que sai”. O segundo conceito está posto contrariamente ao primeiro porque o que entra não necessariamente é o que sai. Assim, "os mediadores transformam, traduzem, distorcem e modificam o significado ou os elementos que supostamente veiculam". Esta diferença conceitual traz um caráter complexo aos atores, fazendo com que os mediadores produzam caminhos que são, como foi dito, uma produção contínua de sociedade.

Uma ação, neste sentido, atua como uma ligação a partir dos diversos atores que desempenham seus papéis, sendo "assumida por outros" (LATOUR, 2012, p. 73). Isto serve como elemento diferenciado, já que a ação revela um caráter mediador, transformador, sendo o ator não apenas o emanante de ações, mas, também, alvo delas, agindo e fazendo agir.

Isso leva a descrever incessantemente como uma ação se desenvolve, uma vez que os mediadores não têm os efeitos de um ato ligado obrigatoriamente a uma causa, mas sim à determinada circunstância que acarreta neste ato. A mediação atua como critério de operacionalização da ação de um actante, isto é, o actante pode ser entendido como um mediador a partir de suas ações.

Latour (2012) é contundente no que se refere a descrições, descartando qualquer tipo de tentativa de explicar o mundo a partir de forças que substituam atores, uma vez que um ator que pode ser substituído é um ator que carrega um viés irrelevante em sua condição de actante. A importância de descrever detalhadamente cada aspecto da rede traz consigo uma visão da realidade, aquilo que é anotado, vivido, pensado, visualizado.

Para realizar este trabalho, o locus selecionado foi o Repositório de Dados de Estudos Ecológicos do Programa de Pesquisa em Biodiversidade (PPBio). Este foi criado pelo Ministério da Ciência, Tecnologia e Inovação (MCTI) em 2004 e está ligado à Convenção sobre Diversidade Biológica (CDB) da Organização das Nações Unidas e às Diretrizes da Política Nacional de Biodiversidade. O PPBio foi criado objetivando articular a competência regional e nacional para que o conhecimento da biodiversidade brasileira seja ampliado e disseminado de forma planejada e coordenada a partir do apoio à implantação e manutenção de redes de inventário da Biota, do apoio à manutenção, ampliação e informatização de acervos biológicos do País, do apoio à pesquisa e desenvolvimento em áreas temáticas da biodiversidade e para o desenvolvimento de ações estratégicas para políticas de pesquisa em biodiversidade (PPBIO, 2005, p. 18-19).

Em relação ao Repositório, trata-se de um sistema via web $^{3}$ que visa prover acesso a um banco de dados que contenha dados científicos sobre a biodiversidade Amazônica, e que parte do princípio que a coleta de dados sobre os indivíduos que compõem esse ecossistema deve estar associada a uma documentação (metadados) e disponibilizada em acesso livre para pesquisadores interessados no tema (PPBIO, 2015). A escolha por este Repositório se deve a sua estrutura no que tange, principalmente, a sua explícita política de dados - como parte do PPBio -, publicada na Portaria 693 no Diário Oficial da União de 20 de agosto de 2009.

A existência de uma política de dados oficialmente instituída por Portaria do Ministro do Estado de Ciência e Tecnologia, consonante com os objetivos do Programa de Pesquisa em Biodiversidade, ocorre devido à:

\footnotetext{
${ }^{3} \mathrm{http} / / /$ ppbio.inpa.gov.br/knb/style/skins/ppbio/

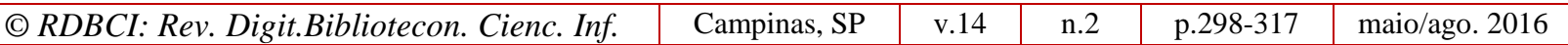


[...] necessidade de um arcabouço de princípios, regras e orientações para todos os participantes do Programa de Pesquisa em Biodiversidade e usuários das bases de dados geradas no âmbito do Programa, no que diz respeito à abrangência, à coleta, ao armazenamento, à propriedade, à autoria, ao compartilhamento, à citação, ao acesso e uso de dados e das bases de dados. (BRASIL, 2009, p. 8).

Também como métodos foram utilizadas a observação não-participante e a entrevista. $\mathrm{O}$ primeiro foi escolhido porque a função investigativa neste trabalho não faz do pesquisador alguém que atue no ambiente observado, bem como o exame de "documentos (livros, jornais, impressos diversos) na medida em que estes não somente nos informam dos resultados das observações e pesquisas feitas por outros mas traduzem também a reação dos seus atores" (RUDIO, 1978, p. 39). Também foram realizadas entrevistas focalizadas, que, embora não sigam uma estrutura formal, permitem a utilização de roteiros expostos em ordem não pré-estabelecida, buscando esclarecimentos sobre a temática envolvida. Essas entrevistas foram realizadas junto aos gestores dos dados no portal PPBio que, além de se caracterizarem como curadores, são especialistas no domínio e autores de dados científicos e documentos bibliográficos.

\section{ALGUMAS CONSIDERAÇÕES SOBRE O (PARADIGMA DO) COMPARTILHAMENTO DE DADOS CIENTÍFICOS}

Em A vida de laboratório: a produção dos fatos científicos, Latour e Woolgar (1997, p. 43) relatam suas experiências dentro de um laboratório e descrevem a questão de produção de uma súmula de dados que se torna relevante: "os tubos, que são manejados com grande cuidado durante uma semana [...], agora perderam qualquer valor. Só há interesse por essa folha cheia de números". Essa folha com dados é parte de uma base de dados que compõe estoques fornecedores de dados primários. Ou seja, não estocam dados bibliográficos e/ou documentos, mas, dados como sequências genéticas, dados de transações financeiras entre outros. Esses dados são insumos para novas pesquisas, também sendo utilizados como forma de comprovação científica de um fato descoberto.

Fica latente que não é apenas a literatura publicada diariamente que alimenta as investigações feitas por pesquisadores e cientistas do mundo inteiro. O processo passa também pelos dados coletados e que ainda podem não ter recebido qualquer tipo de tratamento e/ou interpretação para geração de documentos bibliográficos. São dados científicos primários que podem ser disponibilizados e que são capazes de fundamentar e/ou alavancar pesquisas. São recursos reaproveitáveis, reusáveis, capazes de subsidiar não só uma, mas diversas pesquisas.

A experimentação a partir de dados de pesquisa parece ter se tornado um dos grandes impulsionadores das descobertas e inovações, uma vez que diversas ciências se utilizam de dados científicos para que possam desenvolver seus estudos e promover avanços em suas áreas. Assim, a ideia das ciências, principalmente das ciências na contemporaneidade, é de que os dados têm grande valor como insumo para pesquisa, desenvolvimento e inovação, 
uma vez que os dados por si só não exprimem teorias, mas, a partir de sua análise, é possível construí-las e/ou deduzi-las, auxiliando a interpretação do mundo, permitindo que investigadores sejam capazes de interpretá-los e desenvolver teorias, sistemas etc., inclusive possibilitando a realização de testes, o que é uma regra do jogo científico. Poder realizar testes em dados previamente coletados e anotados com metadados, isto é, reutilizar o que já foi mapeado, possibilita maiores e melhores progressos na ciência, além de oportunizar que recursos financeiros e humanos sejam poupados.

Esse panorama fez com que Gray (2009) observasse e descrevesse uma (r)evolução na ciência e o modo de fazê-la, isto é, a exploração de dados, a qual possibilita que "os dados sejam capturados por instrumentos ou gerados por simulações antes de serem processados pelo software e para a informação resultante ou o conhecimento ser armazenado em computadores" (GRAY, 2009, p. xix).

Esse processo permite com que ciência e tecnologia atuem de forma estreita na produção, gerenciamento, acesso e uso. Ou seja, compreende que "tratar dados, ao invés de ter que coletá-los novamente, possibilita que esforços sejam focados na análise dos dados já existentes e compartilhados, reduzindo custos e esforços e possibilitando avanços efetivamente mais rápidos" (MEDEIROS; CAREGNATO, 2012).

Entendemos que, de fato:

A e-Science promove algo que está ligado à constituição da ciência, isto é, maior possibilidade de cooperação, colaboração e interdisciplinaridade. Necessita-se, entre outros quesitos, de esforços e estudos na forma como os dados são liberados, podendo ser dados fortemente estruturados ou ainda que passaram por um processo de curadoria. (MEDEIROS; CAREGNATO, 2012, p. 320).

Dada a importância e dificuldade da definição, caracterizamos dados científicos, de maneira ampla, recorrendo à definição de Torres-Salinas, Robinson-García e Cabezas-Clavijo (2012):

[...] todo aquele material registrado durante uma pesquisa, reconhecidos pela comunidade científica e que servem para certificar os resultados alcançados. Além destas características, também se especificam que devem provir de uma fonte única e devem ser difíceis ou impossíveis de se obter novamente por serem próprios de um momento ou circunstâncias irreplicáveis de uma forma exatamente igual. (TORRES-SALINAS; ROBINSON-GARCÍA; CABEZAS-CLAVIJO, 2012, p. 175).

De acordo com Borgman (2010), os próprios pesquisadores apresentam dificuldades em manifestar o que são dados científicos, uma vez que sua tipologia é variada. Talvez esta distinção seja o primeiro passo - e um dos mais importantes - para que se possa proporcionar uma infraestrutura de dados científicos. Por exemplo, em Medicina podem ser raios-x, em Química, as estruturas de proteínas, e em Biologia, os espécimes. Pelas tipologias apresentadas, parece-nos claro que a maioria dos dados são criados por e para propósitos de pesquisa, nascidos, atualmente, em formato digital, o que faz com que sejam vistos como parte de um aglomerado que inclui software, equipamento, documentação e conhecimento requeridos para usá-los. 


\section{AUTORIA}

Inicialmente cumpre reconhecer pontos que tornam dificultosa a tarefa de lidar com a noção de autoria. Em primeiro lugar, no que se refere à própria noção, em relação à sua complexidade, é possível constatar que a literatura busca explorá-la e explicá-la de maneira conturbada e plural, o que acarreta em diversas possibilidades de apresentar o tema, bem como certa incipiência. Isso se reflete nas propostas de textos que, ao buscarem tratar a autoria, fixam-se no autor como ente responsável por todo o processo. Pretendemos adiante tornar clara a separação que entendemos existir entre autor e autoria. Em segundo lugar, a dificuldade está colocada em relação ao próprio objeto de nossa pesquisa. Trabalhos sobre autoria estão relacionados, praticamente em sua totalidade, a documentos textuais, gráficos, ficcionais, cinema, teatro etc., ou seja, a literatura busca o entendimento da autoria através do seu discurso, além do indivíduo autor, fazendo com que abordagens para uma explicação a partir de dados científicos digitais ainda não sejam relatadas.

Compreendendo, à luz de Chartier (2002, p. 64), que o "processo de 'publicação' [...] implica sempre uma pluralidade de espaços, de técnicas, de máquinas e de indivíduos" (CHARTIER, 2002, p. 64), podemos aferir que autoria está ligada não exclusivamente a uma entidade, mas a um conjunto de associações que se ligam e desligam de forma a construir uma rede. Dessa maneira, iniciamos uma tentativa de compreender a questão epistemológica da autoria - se assim podemos nos referir - visando trazer a lume a perspectiva levantada por diversos autores, bem como isso pode confluir na capacidade de articular fundamentos que julgamos essenciais a esse entendimento. Para tal, três conceitos aparecem de forma latente em nossas investigações: direito autoral, a autoria propriamente dita e a ética autoral.

\subsection{Direito autoral}

O tema propriedade intelectual vem de longa data, "longe de se originar de uma aplicação particular da definição burguesa do direito de propriedade, [estando ...] profundamente enraizada na defesa de privilégios dos livreiros" (CHARTIER, 2012a, p. 45). Isto é, está voltado à questão econômica, fazendo com que as entidades envolvidas pensem sobre os dividendos que podem gerar.

Os editores livreiros, em Londres no século XVI, tinham o direito de exploração das obras e se utilizavam dessa arma para lutar contra os livreiros oriundos das províncias. Até essa época era utilizado o termo right in copies, direito registrado perpétuo e exclusivo sobre o manuscrito. É somente a partir de 1710 que a Lei para o Encorajamento do aprendizado por meio da concessão de direitos de cópia de livros impressos ao autor, ou compra de tais cópias, fez com que os autores pudessem registrar suas próprias obras, obtendo copyright por um período de 14 anos renováveis por mais 14 anos em caso de autor vivo, e ainda editá-las. Embora o estatuto tenha proporcionado uma nova definição e posição para o autor, isso consistia, basicamente, em uma forma de reiteração de privilégios já estabelecidos (CHARTIER, 2012a, 2012b). 
A criação da imprensa de Gutenberg parece ter alavancado a questão do direito autoral, embora, como diz Campos (1994), esse processo tenha apenas se instituído no século XVIII e contasse com certa vergonha do autor em vender suas ideias e reflexões a um editor. Assim sendo, a forma de exercer o direito sobre algo decorre, necessária e obviamente, da existência desse algo. Isto é, a propriedade intelectual advém da existência de algum bem, fruto de "transformação da natureza, (re)descobrindo-a ou esgotando-a, [aonde] o homem inicia o trabalho idealizando na mente a forma e o processo para ser realizado o objeto, e, em seguida, o abstrato é concretizado" (BARBOSA, 1999, p. 23).

Como aponta Antonio (1998, p. 189), direito autoral diz respeito, essencialmente, “à propriedade intelectual ou artística sobre obras ou produtos. Basicamente, é o direito legal do autor ou criador de uma obra a controlar a reprodução e a distribuição dessa obra". Santos (2009, p. 2) atua na mesma direção ao dizer que "a invenção e a expressão criativa, mais a proteção, são iguais à propriedade intelectual".

Dessas assertivas podemos tirar duas proposições: (i) o direito autoral está ligado à propriedade de um indivíduo/entidade, isto é, fundamenta-se do direito natural, aonde sendo o homem o proprietário do seu corpo, qualquer trabalho por ele produzido implica na sua propriedade; e (ii) o direito autoral está ligado à questão intelectual, não tangível. Com isso, podemos notar que há um tipo de preservação do interesse na continuidade da informação e da evolução, uma vez que formular essas questões "visa não apenas garantir o respeito à propriedade imaterial presente, mas, sobretudo, incentivar a continuidade do trabalho de criação e o conseqüente desenvolvimento social que esta provoca" (CURIA, 2009, p. xv).

Podemos ainda colocar o direito autoral como fundamentalmente instaurado a partir de dois aspectos: o moral e o patrimonial. No que se refere ao primeiro, está ligado à garantia dada ao criador para "o controle à menção de seu nome na divulgação de sua obra e o respeito à sua integridade, além dos direitos de modificá-la ou retirá-la de circulação" (GANDELMAN, 2007, p. 33). No que se refere ao direito patrimonial, basicamente está ligado à utilização econômica da obra criada (CARBONI, 2007).

Em tempos de mudança tecnológica, como foram a criação da imprensa de Gutenberg, a revolução industrial e o desenvolvimento da internet, novas formas de lidar com o direito autoral têm surgido (BRANCO JÚNIOR, 2011), como o caso das licenças públicas. Este tipo de licença surge a partir do momento em que percebemos que "modelos de proteção construídos a partir do final do século XIX são hoje insuficientes para dar conta da revolução tecnológica que vivemos" (BRANCO JÚNIOR, 2011, p. 234), e novos modelos se tornaram necessários para lidar com uma (r)evolução ainda desconhecida, fazendo com que, para além do interesse dos autores e editores, a sociedade possa se beneficiar do conhecimento existente.

\subsection{A autoria}

Buscamos para esta empreitada de investigação, principalmente, dois autores: Michel Foucault e Roger Chartier. Ainda que reconheçamos que nenhum dos dois esgote a questão autor/autoria em seus trabalhos, entendemos que eles disponibilizam grande aporte para compreensão dos elementos que constituem a autoria. 
O próprio Michel Foucault assume que o trabalho com a questão da autoria é por demais complexo. Neste sentido, busca compreender o que está por trás deste processo, aquilo que não foi explicitamente dito. Assim, uma vez que a busca aqui é sobre a compreensão do que está sendo fechado em caixas-pretas a partir de uma maneira racionalmente relatada através das associações que estão postas e formam o coletivo autoria, "trata-se [...] de considerar o autor como função variável e complexa" (CHARTIER, 2012b, p. 27).

$\mathrm{Na}$ introdução à obra $\mathrm{O}$ que é um autor? - A lição de Foucault -, José Bragança de Miranda e António Fernando Cascais relatam a importância de construir o que vem a ser um autor, isto é, não estabelecer uma categoria autor, uma vez que criar categorias implica em construir definições, mas explicitar sua constituição a partir da reunião de elementos. Assim, o que se prospecta é entender a composição do que vem a ser esse elemento, o qual exige explicação, uma vez que as ligações socialmente (ou coletivamente) construídas por esse fenômeno não perpassam apenas ao autor como indivíduo, mas a autoria como processo que envolve atores (atores-rede, na verdade) variados. Estes são, acima de tudo, actantes que interferem diretamente na construção do processo e, por conseguinte, no estabelecimento de "seres inesperados que são necessários para qualquer entidade existir" (LATOUR, 2013, p. 25).

Foucault, na referida obra, parte de uma perspectiva onde o sujeito é visto a partir das formas de representação históricas, com os textos admitindo autoria no momento em que passam a transgredir uma cultura já estabelecida e que, até esse momento, não aceitava contestações. A partir dessa época, quando feitas, acarretavam em punições para quem violasse o sistema estabelecido. Antiguidade para textos literários (narrativas, tragédias, contos etc.) e autoria identificável para textos científicos eram uma padronização praticamente imposta pela época (séculos XIV ao XVIII). Nas palavras de Chartier (2012b, p. 39): "enquanto permaneceu o regime de anonimato para os textos que chamaríamos literários, a presença do nome próprio autorizava, certificava como verdadeiros, os enunciados que chamaríamos científicos".

Ainda que depois haja uma inversão sobre a necessidade de autoria, já que os discursos científicos eram vistos por si mesmos, sem necessidade de verificação de autoria, uma vez que sua credibilidade é vista ligada a "um conjunto sistemático que lhes confere garantias e não a referência ao indivíduo que os produziu" (FOUCAULT, 1997, p. 49), possibilita colocar a função-autor "não apenas ligada à propriedade literária, não somente ligada ao mecanismo e aos dispositivos ${ }^{4}$ de censura, mas também à certificação, à atribuição de verdade" (CHARTIER, 2012b, p. 40).

Foucault nos remete, primordialmente, à questão da responsabilidade, uma vez que,

\footnotetext{
${ }^{4}$ Para fins de clareza, compreendemos dispositivo no sentido que Foucault (2012, p. 364) o estabelece: "conjunto decididamente heterogêneo que engloba discursos, instituições, organizações arquitetônicas, decisões regulamentares, leis, medidas administrativas, enunciados científicos, proposições filosóficas, morais, filantrópicas. Em suma, o dito e o não dito são elementos do dispositivo. O dispositivo é a rede que se pode estabelecer entre esses elementos". O autor segue sua explicação do que entende por dispositivo, alertando para as relações que os elementos podem estabelecer entre si, independentemente de sua natureza, agindo como players que podem fazer com que a rede e, consequentemente, seus movimentos sejam alterados funcionalmente e suas articulações ajam como respostas a uma inquirição julgada necessária para aquele momento.
}

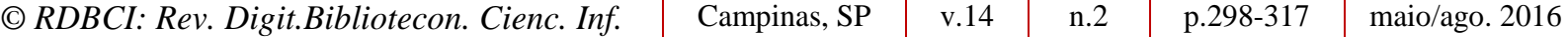


para ele, o escrito necessita de um autor para que haja punição - responsabilização - pelo seu dito, fazendo com que o autor seja:

[...] aquilo que permite explicar tanto a presença de certos acontecimentos numa obra como as suas transformações, as suas deformações, as suas modificações diversas (e isto através da biografia do autor, da delimitação da sua perspectiva individual, da análise da sua origem social ou da sua posição de classe, da revelação do seu projeto fundamental). $O$ autor é igualmente o princípio de uma certa unidade de escrita, pelo que todas as diferenças são reduzidas pelos princípios da evolução, da maturação ou da influência. O autor é ainda aquilo que permite ultrapassar as contradições que podem manifestar-se numa série de textos: deve haver - a um certo nível do seu pensamento e do seu desejo, da sua consciência ou do seu inconsciente - um ponto a partir do qual as contradições se resolvem, os elementos incompatíveis encaixam finalmente uns nos outros ou se organizam em torno de uma contradição fundamental ou originária. Em suma, o autor é uma espécie de foco de expressão, que, sob formas mais ou menos acabadas, se manifesta da mesma maneira, e com o mesmo valor, nas obras, nos rascunhos, nas cartas, nos fragmentos, etc. (FOUCAULT, 1997, p. 53-54).

Seguindo com Foucault, são apresentadas características do que o filósofo compreende como a função-autor. A primeira característica está ligada à questão punitiva, uma vez que os escritos ultrapassam a divisão entre o sagrado e o profano. Ou seja, há atribuição de autoria a indivíduos, não mais a seres intocáveis ou imaculados ou sagrados, fazendo com que os indivíduos fossem responsabilizados e punidos pelos seus discursos contra os costumes impostos (FOUCAULT, 1997). A segunda característica da função-autor está ligada à colocação do discurso no tempo e na cultura, ou seja, em relação ao seu contexto ou, ainda como relata Foucault (1997, p. 48), "a função autor não se exerce de forma universal e constante sobre todos os discursos". A terceira é a complexidade que envolve essa função, uma vez que "ela não se forma espontaneamente como a atribuição de um discurso a um indivíduo. É antes o resultado de uma operação complexa que constrói um certo ser racional a que chamamos de autor" (FOUCAULT, 1997, p. 50). A última característica diz que o autor é uma pluralidade de "eus", onde cada indivíduo pode apresentar posições e discursos diferenciados para cada momento.

O entendimento de Foucault é que existe uma pluralidade de posições que tomam o indivíduo como autor, isto é, o autor não é um ente solitário, mas, sim, um arranjo de posicionamentos, formas de pensar e criar, advindas de antecedentes culturais, bem como por indivíduos que colaboram ou que concorrem com ele (CHARTIER, 2012b).

A função-autor é assim resumida por Foucault (1997, p. 56-57):

\begin{abstract}
Resumi-los-ei assim: a função autor está ligada ao sistema jurídico e institucional que encerra, determina, articula o universo dos discursos; não se exerce uniformemente e da mesma maneira sobre todos os discursos, em todas as épocas e em todas as formas de civilização; não se define pela atribuição espontânea de um discurso ao seu produtor, mas através de uma série de operações específicas e complexas; não reenvia pura e simplesmente para um indivíduo real, podendo dar lugar a vários 'eus' em, simultâneo, a várias posições-sujeitos que classes diferentes de indivíduos podem ocupar. (FOUCAULT, 1997, p. 56-57).
\end{abstract}

Dessa forma, para Foucault, a função-autor é algo relacionado à posição do sujeito, 
isto é, um aspecto do indivíduo que é atravessado por questões culturais, políticas, sociais, econômicas, temporais, entre outras, enfim, a construção e colocação do sujeito como ator social de um mundo complexo. Entre o autor e a pessoa do autor, a entidade autor só existe do corte entre as entidades, a partir dos múltiplos "eus", ou seja, numerosos egos.

O que enxergamos é que tanto Foucault (1997) quanto Chartier (2012a, 2012b) estão preocupados com a função-autor pela "maneira como o texto aponta para essa figura que lhe é exterior e anterior, pelo menos aparentemente" (FOUCAULT, 1997, p. 34). Isso reflete no que viemos argumentando, ou seja, a análise que deve ser levada em conta, para além do autor, é uma argumentação de autoria, de ligações desse conceito/processo que se estabelece em forma de rede, podendo ser considerado um ator-rede.

Assim sendo, advogamos que o nosso interesse não recai no autor, mas sim na autoria. Embora entendamos que o termo autor destaca os elementos que estão ao redor do conceito/entidade, parece-nos estar ligado à pessoa, fazendo com que a análise recaia sobre o indivíduo como forma humanizada, sendo alvo de um estudo quase psicológico. Dessa forma, nossa preferência está colocada no termo autoria, o qual compõe o processo como um todo e comporta, à luz da Teoria Ator-Rede, um modo de entender os objetos, conceituais ou pragmáticos, atuantes na construção do elemento.

\section{3 Ética autoral}

A noção de ética aqui exposta está ligada ao seu acontecimento na ciência, principalmente do que chamamos de ciência moderna a partir do século XVII. A isso se soma a grande dependência do ser humano a diversos objetos tecnológicos, alterando a forma de atuação do homem com o mundo e da relação do mundo com o homem, bem como suas questões éticas e morais. Assim, podemos compreender, à luz de Droit (2012, p. 10), que as questões éticas "referem-se ao sentido da vida, aos limites das nossas intervenções sobre a matéria viva, ou ainda à dignidade humana". Isto nos remete ao que está no cerne da ética, ou seja, a liberdade, as escolhas feitas pelos indivíduos.

A liberdade, no entanto, compreende uma questão restritiva, uma vez que como lembra Fourez (1995), a ética está ligada àquilo que é desejável em um contexto históricosocial envolto em perspectivas de valores, ideologias etc. nas relações. Há sempre uma posição de comportamento, um modo de ver e colocar as coisas na discussão, uma apropriação que se baseia em uma ótica de vida e que nunca é neutra. Em decorrência, se comportamento está por trás da moral e, por consequência, da ética ${ }^{5}$, compreendê-la é entender "uma forma de conhecimento que diz respeito aos comportamentos" (DROIT, 2012, p. 15).

Apoiamo-nos, neste sentido, em Sánchez Vásquez (1987, p. 12) para definirmos ética: "[...] teoria ou ciência do comportamento moral dos homens em sociedade. Ou seja, é ciência de uma forma específica de comportamento humano”. Assim sendo, além de um caráter

\footnotetext{
${ }^{5}$ É oportuno realizar uma diferenciação entre moral e ética. Segundo Sánchez Vásquez (1987), além de agir moralmente em atitudes cotidianas, como problemas relacionais e tomada de decisões, necessitamos de reflexão sobre esses comportamentos, isto é, na passagem da prática para o pensamento reflexivo sobre ela passamos à ética.
} 
científico que visa abordar características universais de seu objeto de estudo, descreve conceitos, teorias, hipóteses etc. que expliquem o fato moral de forma sistemática, metódica e comprovável.

Aportando na contemporaneidade e percebendo os avanços da tecnologia que tendem a nos colocar em frente a questões nem sempre claras, as respostas podem não ser únicas, uma vez que a moral de uma comunidade pode não ser compartilhada por outra (DROIT, 2012). Assim, trabalhar a ética permite pensar os atos diretos e indiretos das entidades envolvidas no processo de autoria de dados científicos. Por este motivo, e para o contexto deste trabalho, a questão da ética está ligada à ciência e a forma como os dados científicos se relacionam com a autoria.

A ideia é compreender, como propõe Silva Filho (2009, p. 9), a razão dos acontecimentos, ou seja, "conceber por razão aquilo que, num quadro discursivo, explica uma ação". Isto é, exercitarmos a capacidade descritiva da vida humana - em nosso caso a questão autoral - e suas escolhas/atitudes em determinado contexto, uma vez que "uma ação moral [...] não apenas se é uma 'boa ação', mas se é expressão de uma decisão livre e racional" (SILVA FILHO, 2005, p. 88), possibilitando realizar escolhas baseadas em julgamentos e razões para escolher $\mathrm{A}$ em detrimento de $\mathrm{B}$.

Isso impacta, obrigatoriamente, na responsabilidade do pesquisador/autor perante a autoria dos dados científicos. Neste sentido, a pergunta mais pertinente seria: qual a responsabilidade do pesquisador? Droit (2012, p. 61) mostra que quando estamos refletindo questões éticas, "há de fato a ideia de que nós criamos nossas próprias ações, de que decidimos fazer isto ou aquilo, e, portanto, de que somos responsáveis. Em toda forma ética há uma concepção de responsabilidade".

Nisso é relevante perceber que o impacto das tecnologias da informação e da comunicação têm efeito além dos profissionais que lidam com esses aparatos, mas influenciam a sociedade como um todo, seja na relação homem-homem, seja na relação homem-máquinas/instrumentos, seja - por que não? - na relação máquinas/instrumentosmáquinas/instrumentos. "A ciência e a tecnologia tiveram uma parte bem significativa na organização da sociedade contemporânea, a ponto de esta não poder prescindir das primeiras: energia, meios de transporte, comunicações, eletrodomésticos etc.” (FOUREZ, 1995, p. 207).

Se considerarmos que os sistemas eletrônicos mantêm interação com humanos e não humanos - como admite a Teoria Ator-Rede -, estamos diante de novos problemas morais e, por consequência, éticos que estão refletidos em diversos aspectos nos dados científicos primários, inclusa a questão autoral. Com isso, devemos sublinhar a existência de normas universais sem relegar, no entanto, os aspectos históricos e sociais de uma entidade ou de um ambiente social, exigindo pensar a ética de forma a levar em consideração as macro e as micro situações envolvida neste processo, proporcionando uma análise descritiva das ações.

\section{ELEMENTOS EM AÇÃ̃o}

Ao reconhecermos a complexidade do objeto de estudo, buscamos nesta seção uma espécie de reunião dos elementos que formam a razão da autoria de dados científicos, os

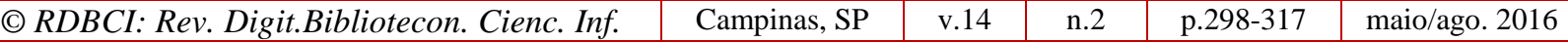


quais compreendem aspectos simétricos dos atores, humanos e não humanos, possibilitando a compreensão das associações entre elementos heterogêneos. Essa reunião busca coligir "um tipo de conexão entre coisas que não são, em si mesmas, sociais" (Latour, 2012, p. 23), onde a reunião desses elementos visa agrupar as matérias, aplicações, ferramentas, conceitos, práticas etc. heterogêneas, já que o social é "um movimento peculiar de reassociação e reagregação" (LATOUR, 2012, p. 25) constante, permitindo usufruir do que há de social em cada ator-rede.

Compreendemos que a construção de um fato científico e social, como a autoria, é coordenada por uma série de elementos que foram levantados com o auxílio da ANT e que podem ser vistos como mediadores. Elementos como a coleta de dados, a curadoria, os próprios dados científicos, seus metadados, as fontes de fomento, a política de dados, o repositório e seus softwares de gerenciamento e envio de dados e metadados, o licenciamento, a propriedade e a responsabilidade.

O primeiro ponto que gostaríamos de trazer diz respeito à coleta técnica. Quando um pesquisador se dirige a um sítio, parcela ou qualquer outra área de coleta de dados, está imbuído de um senso técnico para trazer à tona detalhes de sua observação do mundo que o rodeia, no caso, aspectos da biodiversidade da Amazônia. No entanto, minúcias relacionadas à tabulação de dados podem ser facilmente deixadas de lado devido a não ser dada a merecida atenção aos aspectos de forma que devem ser contemplados para que os dados possam ser inseridos e disponibilizados no Repositório. Cabe ao pesquisador a consciência e a instrução sobre os procedimentos a serem adotados, como, por exemplo, a capacitação para coleta e tabulação de dados e o suporte técnico que abrangem a curadoria.

Somado a isso está a preocupação em preservar os dados e, por consequência, o conhecimento contido neles a partir tanto do cuidado já descrito, isto é, uma tabulação e uma documentação condizente com os dados e sua possível (re)utilização, bem como todo aparato tecnológico utilizado para possibilitar sua recuperação e assim possibilitar novos estudos e/ou aplicações em serviços e/ou bens para a sociedade.

Isso é consonante com a estratégia que o compartilhamento de dados científicos e a eScience visam promover, algo próximo do que Gray (2009) chama de um novo modelo de ciência, com dados gerando novos conteúdos, a partir do tratamento, da produção, do gerenciamento, do acesso e do reúso dos dados em grandes centros de dados ou em computadores pessoais, poupando, assim, esforços humanos e financeiros. Promover o compartilhamento dos dados é promover um maior alcance e maior eficácia da ciência, fazendo com que ela atue como um bem e um serviço social.

Outro atuante que devemos levar em consideração são as agências de fomentos. Ao compreender que essas existem no sentido de amparar pesquisas para algum propósito, seja ele social, econômico, entre outros, deve haver uma separação entre os fundos privados e públicos. Quando se trata de um fundo privado, o interesse do investidor é, a partir de certa aplicação - geralmente financeira - na área, obter retorno no que diz respeito ao desenvolvimento de melhores produtos e, por consequência, competir em determinada fatia de mercado e obter lucros. Ao se trabalhar com fundos públicos, o que se pretende é estimular a produção de um local (país, região, estado etc.), aplicando recursos em áreas, geralmente, estratégicas e multidisciplinares, com vistas a alavancar a produção do local e

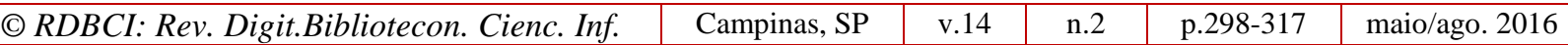


melhorar a qualidade de vida de seus cidadãos.

Assim, o grande mote desses dados é proporcionar, através de uma política de dados, a possibilidade de que as agências financiadoras possam ter acesso e (re)utilizar os dados, buscando benefícios para os cidadãos. Isso parece ficar claro na Política de dados do PPBio, já que ela está preocupada, entre outras coisas, com a difusão conhecimento, bem como o desenvolvimento de sistemas eletrônicos capazes de tratar o que pode se tornar informação sobre a biodiversidade brasileira e suas consequências em âmbitos econômico e social.

Nesse sentido, a popularização de normas pelas agências de fomento, como vistas a exigir a liberação de dados coletados em pesquisa com financiamento, proporciona, além da geração de novos conhecimentos, o estabelecimento de uma cultura de participação, de envolvimento, de engajamento nas questões sociais e na preocupação com o bem-estar dos cidadãos. Prestar contas para a sociedade é um começo para pensar um fluxo contínuo de reúso e preocupação/consciência social.

Pensando, então, no caráter público dos recursos que subsidiam pesquisas, com especial atenção para a biodiversidade, foco no nosso trabalho, é correto pensar que o ente público atua como um tipo de detentor desse conhecimento, sendo necessário que haja um local para depósito e disponibilização desses dados. Em nosso caso, o Repositório de Dados Ecológicos do PPBio.

A importância dos repositórios está na possibilidade de que eles proporcionam acesso universal à grande quantidade de dados/informação científica, possibilitando que a visibilidade de autores e instituições, bem como dos próprios dados que agregam, seja potencializada. Tomando consciência disso, parece lógico chegar à compreensão da função do Repositório como importante dispositivo de compartilhamento de dados - também informação e conhecimento -, promovendo, para além da disponibilização dos dados, a integração entre pesquisadores e instituições.

Isso parece mais claro quando aceitamos que os dados científicos de pesquisa são, além de representativos de uma realidade, de uma materialidade, de determinados aspectos da natureza, são construtos sociais. Ou seja, advêm da natureza e da operação do homem com ela e atuam em uma constante mutação do que vivemos hoje em dia, sendo modificados não apenas a partir de desafios tecnológicos, mas sociais e políticos. Isso também está ligado aos metadados, produtos da documentação dos dados científicos. Vemos também que definir dados de pesquisa ainda é algo complexo para pesquisadores que trabalham com coleta de dados. Não existe, como podemos aferir, uma separação entre dados e metadados, uma vez que há necessidade de coexistência de ambos elementos. Dados sem metadados têm capacidade minimizada de cumprir sua função, quiçá inutiliza-los.

O Repositório, e sua atuação como meio de disseminação de dados, parte dos dados e metadados, suportado pelas aplicações de gerenciamento do próprio repositório e do envio de dados e metadados, agindo como centro útil para depósito, promovendo também o reconhecimento científico daqueles que coletam e sistematizam um conjunto de dados, isto é, os autores. Isso é possível a partir da interface de acesso aos dados, onde é permitido realizar pesquisas a partir da documentação do conjunto de dados e ter acesso à listagem de conjuntos recuperados com base na expressão de interesse utilizada no momento da busca.

Ao reconhecimento científico está ligada diretamente outra questão, o licenciamento

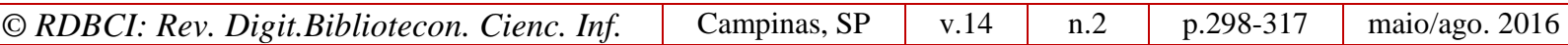


de dados. Esse processo pouco explorado no contexto do PPBio pode afetar de maneira substancial a forma como a autoria está posta. Como a intenção é promover algo que possa ser de utilidade para o contexto de pesquisa do Programa, as pendências que seriam geradas com a discussão de direitos autorais são, em geral, deixadas de lado, simplificando - ou nos arriscando a dizer, mostrando falta de debate sobre esse conteúdo - a forma de disponibilizar acesso aos dados. Também é importante frisar que essa é uma preocupação do Programa, mas não a mais importante, sendo, em primeiro lugar, dada importância à disponibilização para reúso. O que se vê, desse modo, é que direito autoral está ligado ao aspecto moral da relação estabelecida entre o autor e sua obra que também é, ao mesmo tempo, patrimonial - em outras palavras, um bem econômico.

Chegando à propriedade, com base no que foi narrado, podemos dizer que não há preocupação profunda com essa questão. É claro que existe a ideia de garantir a autoria a quem deve ser creditada, mas isso passa por uma questão moral por parte do reutilizador. $\mathrm{Ou}$ seja, com base na Política de dados, há indicação para que o autor dos dados científicos seja contatado para saber da sua possibilidade de participar de novos estudos com base em reúso. Isso promove, para além do sentido de propriedade, um sentido de que os dados possam ser úteis para um indivíduo que desenvolve seus estudos ou para a sociedade como um todo. Essa promoção da utilidade dos dados para fins científicos e sociais provoca interações entre os pesquisadores e suas instituições.

A utilização de licenciamentos, assegurando os direitos autorais, parece primordial para, além de conferir responsabilidade, possibilitar que os indivíduos se sintam confortáveis a colaborar de forma mais segura, tendo certeza de que os dados depositados no Repositório terão o crédito reconhecido, percebendo que novos projetos podem vingar a partir da interação e da colaboração com outros pesquisadores.

O último item que elencamos em nossa reunião de elementos é a responsabilidade. Este elemento conceitual traz uma série de implicações que permeiam o processo de autoria de início a fim. Tem sua formação na coleta, no compartilhamento e também no reúso dos dados, deixando traços, inclusive, na percepção sobre que tipo de dados devem ser coletados e liberados para disseminação, o que estaria próximo da "possibilidade de prever os efeitos do próprio comportamento e de corrigi-lo com base em tal previsão" (ABBAGNANO, 2007, p. 855).

Pensar a responsabilidade como conceito ator-rede é primordial em diversos sentidos, mas a literatura dispõe de pouco conteúdo sobre a relação entre ética e autoria e, em consequência, sobre responsabilidade autoral, mas esse ponto é de extrema relevância como a construção do conceito de autoria, uma vez que a responsabilização pode trazer um caráter de reconhecimento ou de punição, caso, por exemplo, dados inconsistentes causem algum tipo de dano ao sistema ecológico.

\section{CONSIDERAÇÕES FINAIS}

A autoria age como um tipo de instrumentalização de um arranjo de fenômenos, isto é, uma ferramenta que, atuante como conceito e/ou como processo, permite que seja

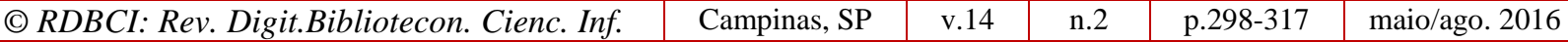


consolidado um sistema de comportamento, instituído a partir de regras explícitas - como a política de dados - bem como regras implícitas, originárias de um longo período de embates, acordos e símbolos científicos, sendo possível depreender que a autoria mantém vínculo com normas, com regras e com diretrizes. Ao compreendermos que as próprias normas são advindas dos sujeitos e suas associações, e por isso seus interesses, percepções, posições políticas etc., os indivíduos já posicionam o coletivo como a entidade a ser analisada. Este coletivo é, por tudo que defendemos neste trabalho, um processo de resgate de posições, de compreender atores que são redes e não podem ser vistos separadamente, sendo, sem dúvida, coletivamente existentes.

O que estabelecemos aqui é a compreensão de que os procedimentos ligados à autoria de dados científicos são, em essência, conceituais em forma, sem descartar o ferramental pragmático utilizado. Não estamos ligados, nesse sentido, a um processo exclusivamente maquinário e/ou tecnológico, já que isso poderia tornar a análise um apelo reservado ao imperativo tecnológico, mas, sim, aos atores-rede conceituais que formam a ideia de autoria e que fecham a caixa-preta que buscamos abrir ou, pelo menos, estabelecer menor opacidade.

Mesmo em forma de objetos conceituais, apreender esses atores-rede é compreender a sua igualdade, simetria, fazendo com que as relações entre humanos e não humanos não sejam denominadas por um nome, mas por ações que modificam um cenário. Assim, vistos como funções conceituais, seus "usos" são incertos por outros atores, mas compõem uma gama de associações que constroem o conceito de autoria.

Podemos concluir que não há autoria fora da ação. Embora isso seja algo que parece óbvio, - e o é se pensarmos que nenhum tipo de coleta/posição/discurso ocorre fora de um contexto de ação - remete-nos a tessitura do fato, à criação de um objeto complexo, como a autoria, a partir de um emaranhado coletivo, colaborativo em essência, cercado por uma contextualização de tempo e espaço. Em consequência, há de se atribuir a esse processo a responsabilidade por seus atos, arcando com o bônus e o ônus de pensar e de agir, de refletir e de promover modos de anotações, de escritas, de dados. Isso nos parece ser consoante ao que Foucault descreve como função-autor.

Esses processos podem ser vistos como convênios, ou seja, um tipo de contrato social e estão colocados entre os indivíduos autores e os atos de autoria, as instituições que são utilizadas como depósito e disseminadoras de dados, bem como as questões políticas e éticas envolvidas no processo. Esse grande espectro leva à responsabilidade da autoria, isto é, a autoria é um ato que congrega autonomia e responsabilidade visando busca por reconhecimento e persuasão de determinado público. A autonomia está colocada na criação de determinado conjunto de dados e a responsabilidade está pautada na questão ética. $\mathrm{Ou}$ seja, não há autoria apenas com o autor, mas também a partir de uma série de mediadores, humanos e não humanos, instrumentais e conceituais.

Por fim, podemos considerar a autoria um tipo híbrido de convênio conceitual, ou seja, é um acordo sobre determinada atividade e/ou assunto que se estabiliza a partir de tratados previamente estabelecidos. Ainda é relevante notar que esses tratados podem ou não ser percebidos como tal, havendo possíveis conjecturas não entendidas per se ou explicitadas. No entanto, no fulcro de qualquer questionamento está a compreensão do que é autoria, uma vez que esse conceito liga o insumo ao conhecimento gerado, passando pelo 
compartilhamento e pela colaboração.

\section{REFERÊNCIAS}

ABBAGNANO, Nicola. Dicionário de filosofia. 3. ed. São Paulo: Martins Fontes,2007. $1014 \mathrm{p}$.

ANTONIO, Irati. Autoria e cultura na pós-modernidade. Ciência da Informação, Brasília, v. 27, n. 2, p. 189-192, maio/ago. 1998. Disponível em: <http://www.scielo.br/pdf/ci/v27n2/irati.pdf>. Acesso em: 7 maio 2014.

BARBOSA, A. L. F. Proteção do trabalho intelectual. In: Sobre propriedade do trabalho intelectual: uma perspectiva crítica. Rio de Janeiro: UFRJ, 1999. p. 21-87.

BORGMAN, Christine. Scholarship in the digital age: information, infrastructure, and the Internet. Cambridge, Massachusetts; London, England: MIT Press, 2010. 336 p.

BRANCO JÚNIOR, Sérgio. Vieira. Fundamentos para o domínio público no direito autoral brasileiro, Liinc em Revista, v. 7, n. 2, p. 437-465, set. 2011. Disponível em: <http://revista.ibict.br/liinc/index.php/liinc/article/view/439/328>. Acesso em: 15 mar. 2015.

BRASIL. Portaria no 693 de, 20 de agosto de 2009. Institui, no âmbito do Programa de Pesquisa em Biodiversidade - PPBio, a Política de Dados. Diário Oficial da União, Poder Executivo, Brasília, DF, 21 ago. 2009, Seção 1, p. 8-9.

CAMPOS, Arnaldo. O direito de autor. In: Breve história do livro. Porto Alegre: Mercado Aberto, 1994. (Série Revisão; 40).

CARBONI, Guilherme. O direito de autor e seus desafios: os conflitos com a liberdade de expressão, o direito de acesso ao conhecimento, à informação e à cultura e o direito ao desenvolvimento tecnológico. In: REIS, R. et al. (Org.). Propriedade intelectual: interfaces e desafios. Rio de Janeiro: ABIA, 2007. p. 59- 123.

CHARTIER, Roger. História intelectual do autor e da autoria. In: FAULHABER, P.; LOPES, J. S. L. Autoria e história cultural da ciência. Rio de Janeiro: Beco do Azougue, 2012a. p. 37-64.

CHARTIER, Roger. O que é um autor? Revisão de uma genealogia. São Carlos: EDUFSCAR, 2012b. 90 p.

CHARTIER, Roger. Os desafios da escrita. São Paulo: UNESP, 2002. 144 p.

CURIA, Luis Roberto. Apresentação. In: SANTOS, Manuella. Direito autoral na era digital: impactos, controvérsias e possíveis soluções. 2009. São Paulo: Saraiva. 2009. p. xvxvii.

DROIT, Roger-Pol. Ética: uma primeira conversa. São Paulo: Martins Fontes, 2012. 95 p.

FOUCAULT, Michel. Microfísica do poder. 25. ed. São Paulo: Graal, 2012. 
FOUCAULT, Michel. O que é um autor? 3. ed. Lisboa: Vega, 1997. 160 p.

FOUREZ, Gérard. A construção das ciências: introdução à filosofia e à ética das ciências. São Paulo: UNESP, 1995. 319 p.

FREIRE, Leticia de Luna. Seguindo Bruno Latour: notas para uma antropologia simétrica. Comum, Rio de Janeiro, v. 11, n. 26, p. 46-65, jan./jun. 2006. Disponível em: $<$ http://www.ifcs.ufrj.br/ lemetro/pesquisadores/Leticia\%20de\%20Luna\%20Freire/lat our.pdf>. Acesso em: 14 maio 2013.

GANDELMAN, Henrique. De Gutenberg à internet. 5. ed. rev. e ampl. Rio de Janeiro: Record, 2007. 295 p.

GRAY, Jim. Jim Gray on escience: a transformed scientific method. In: HEY, Tony; TANSLEY, Stewart; TOLLE, K. (Ed.). The fourth paradigm: data-intensive scientific discovery. Washington: Microsoft Research, 2009. Disponível em: $<$ http://research.microsoft.com/enus/collaboration/fourthparadigm/4th_paradigm_book_jim_gray_transcript.pdf $>$. Acesso em: 20 maio 2013.

LATOUR, Bruno. A esperança de Pandora: ensaios sobre a realidade dos estudos científicos. Bauru: EDUSC, 2001.

LATOUR, Bruno. Ciência em ação: como seguir cientistas e engenheiros sociedade afora. São Paulo: UNESP, 2000. 438 p.

LATOUR, Bruno. Jamais fomos modernos: ensaio de antropologia simétrica. 2. ed. São Paulo: Ed. 34, 2009. 150 p.

LATOUR, Bruno. Reagregando o social: uma introdução à Teoria Ator-Rede. Salvador; Bauru: EDUFBA; EDUSC, 2012. 399 p.

LATOUR, Bruno. Redes, sociedades, esferas: reflexões de um teórico ator-rede. Informática na Educação: teoria e prática, Porto Alegre, v. 16, n. 1, jan./jul. 2013. Disponível em: <http://seer.ufrgs.br/index.php/InfEducTeoriaPratica/article/view/36933/25939>. Acesso em: 4 nov. 2013.

LATOUR, Bruno; WOOLGAR, Steve. A vida de laboratório: a produção dos fatos científicos. Rio de Janeiro: Relume Dumará, 1997. 310 p.

LEMOS, André. Você está aqui! Mídia locativa e teorias "materialidades da comunicação" e "ator-rede". Comunicação \& Sociedade, ano 32, n. 54, p. 5-29, jul./dez. 2010.

MEDEIROS, Jackson da Silva; CAREGNATO, Sônia Elisa. Compartilhamento de dados e eScience: explorando um novo conceito para a comunicação científica. Liinc em Revista, v. 8, n. 2, p. 311-322, 2012. Disponível em: <http://revista.ibict.br/liinc/index.php/liinc/article/viewFile/488/373>. Acesso em: 10 maio 2013. 
MORAES, Márcia. A ciência como rede de atores: ressonâncias filosóficas. História, Ciências, Saúde - Manguinhos, Rio de Janeiro, v. 11, n. 2, p. 321-333, 2004.

PEREIRA, Ana Lúcia Lage. A rede como espaço multirrefencial de aprendizagem: construção do conhecimento na produção de inovação em TIC em um Instituto de Ciência e Tecnologia brasileiro. 2013. 267 f. Tese (Doutorado em Difusão do Conhecimento)Faculdade de Educação, Universidade Federal da Bahia, Salvador, 2013.

PROGRAMA DE PESQUISA EM BIODIVERSIDADE (PPBIO). 2015. Disponível em: <http://ppbio.inpa.gov.br >. Acesso em: 16 mar. 2015.

RUDIO, Franz Victor. Introdução ao projeto de pesquisa científica. Petrópolis: Vozes, 1978. 144 p.

SÁNCHEZ VÁSQUEZ, Adolfo. Ética. 10. ed. Rio de Janeiro: Civilização Brasileira, 1987. $267 \mathrm{p}$.

SANTOS, Manuella. Direito autoral na era digital: impactos, controvérsias e possíveis soluções. São Paulo: Saraiva. 2009. 182 p.

SILVA FILHO, Waldomiro José da. Considerações pós-éticas sobre a ação e a racionalidade. In: TEIXEIRA, A. (Org.). Especificidades da ética na Psicanálise. Salvador: Associação Científica Campo Psicanalítico, 2005. p. 86-97.

SILVA FILHO, Waldomiro José da. Ética sem fundamentos. In: GOMES, H. F.; BOTTENTUIT, A. M.; OLIVEIRA, M. O. E. (Org.). A ética na sociedade, na área da informação e da atuação profissional: o olhar da Filosofia, da Sociologia, da Ciência da Informação e da formação e do exercício profissional do Bibliotecário no Brasil. Brasília: Conselho Federal de Biblioteconomia, 2009. p. 9-29.

TORRES-SALINAS, Daniel; ROBINSON-GARCÍA, Nicolás; CABEZAS-CLAVIJO, Álvaro. Compartir los datos de investigación em ciência: introducción al data sharing. EI profesional de la información, v. 21, n. 2, p. 173-184, mar./abr. 2012.
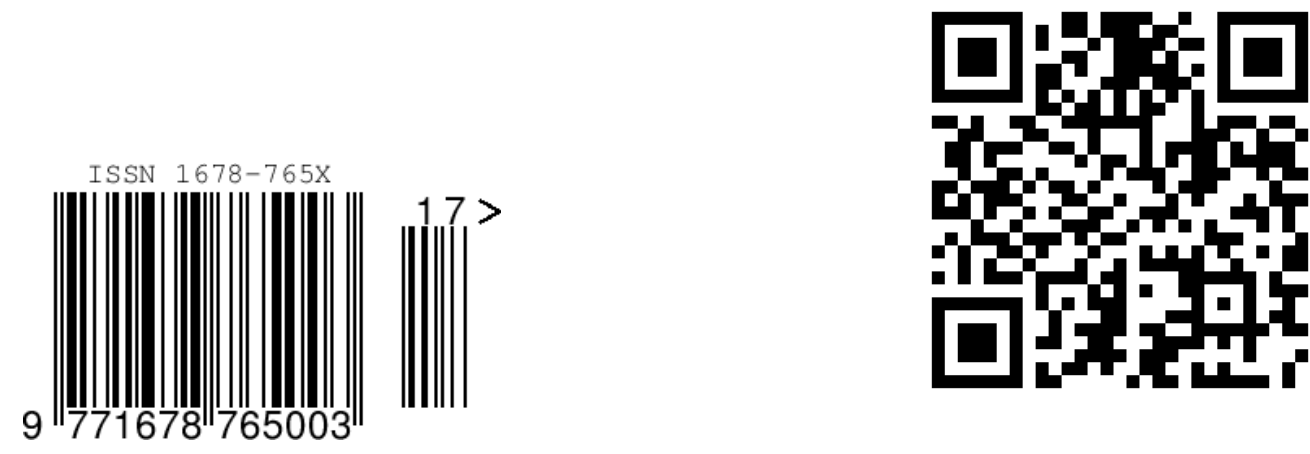